\title{
Septum Secundum
}

National Cancer Institute

\section{Source}

National Cancer Institute. Septum Secundum. NCI Thesaurus. Code C34295.

A thick growth on the atrial wall, located to the right of the initial septum primum in the early embryo; it forms an incomplete partition between the atria, leaving only an area at the posterosuperior part of the interatrial septum: the fossa ovalis. 